\title{
REINFORCEMENT OF NATURAL RUBBER BY PRECIPITATED SILICA: THE INFLUENCE OF PROCESSING TEMPERATURE
}

\author{
By S. Salina Sarkawi ${ }^{1,2^{*}}$, Wilma K. Dierkes ${ }^{1}$, Jacques W.M. Noordermeer ${ }^{1}$ \\ ${ }^{1}$ University of Twente, Elastomer Technology and Engineering, P.O. Box 217, \\ 7500 AE Enschede, the Netherlands \\ ${ }^{2}$ Malaysian Rubber Board, RRIM Research Station, Sg. Buloh, \\ 47000 Selangor, Malaysia
}

Presented at the Fall $182^{\text {nd }}$ Technical Meeting of the

Rubber Division of the American Chemical Society, Inc.

Cincinnati, Ohio

October $9-11,2012$

ISSN: $1547-1977$

*Speaker 


\begin{abstract}
The thermal history and in particular the mixing dump temperature is a parameter of paramount importance in mixing rubber and silica with a silane coupling agent in order to achieve proper silanization of silica and to avoid premature scorch reactions. In this work, the influence of mixing dump temperature on the performance of silica reinforced Natural Rubber (NR) is investigated. The investigation also includes the effect of non-rubber constituents, primarily proteins in NR, by using deproteinized Natural Rubber (DPNR) and synthetic polyisoprene (IR). The vulcanization properties and rubber-to-filler interactions of silica reinforced NR in presence and absence of a silane coupling agent are highlighted. With increasing mixing dump temperature, the silanization reaction between silica and silane coupling agent proceeds further. At sufficiently high dump temperature, filler-filler interactions in the NR-silica compounds are reduced and silica-rubber interaction improved as evidenced by a drop in the Payne effect and increment in chemically bound rubber. It is demonstrated that NR and IR compounds mixed till above the optimum dump temperature exhibit cure reversion and reduction in tensile properties. On the other hand, DPNR-silica vulcanizates show slightly more constant physical properties.
\end{abstract}




\section{INTRODUCTION}

Compared to carbon black filled materials, mixing of silica compounds involves many difficulties due to the large polarity difference between silica and rubber. A bifunctional organosilane such as bis (triethoxy silylpropyl) tetrasulfide (TESPT) or its disulfide equivalent is commonly used as coupling agent ${ }^{1}$ in enhancing the compatibility of silica and rubber, by chemically modifying silica surfaces and eventually creating a chemical link between silica aggregates and the rubber chains: Figure 1. Complications arise during mixing silica compounds as several chemical reactions need to take place, all at their appropriate time slots during rubber processing, namely the silica and silane reaction or silanization, silanerubber coupling and crosslinking between the rubber chains ${ }^{2}$. The highly-dispersible silica technology, as it is used today, employs mainly solution-polymerized synthetic rubber, and is still not fully commercially feasible with Natural Rubber (NR $)^{3}$. It was postulated that nonrubber constituents contained in NR such as proteins compete with the coupling agent for reaction with the silica during mixing, so disturbing its reinforcement action.

$\mathrm{NR}$ is a unique material with outstanding properties, such as high tensile strength, good resilience and low heat build-up, superior to synthetic polyisoprene (IR). NR derived from Hevea Brasiliensis latex contains about 3-5\% of non-rubber constituents ${ }^{4}$, essentially proteins and phospholipids, while in contrast IR has none. The structure of a linear NR chain consists of a long sequence of 1000 - 3000 cis-1,4 isoprene units, two trans-1,4 isoprene units, with $\alpha$ - and $\omega$-chain ends ${ }^{5}$. The $\alpha$ - and $\omega$-terminals are associated with phospholipids and proteins respectively ${ }^{6-7}$, and are presumed to play a part in the branching and gel formation in $\mathrm{NR}^{8}$. IR, synthetically produced from isoprene, may contain between $90-98 \mathrm{wt} \%$ cis-1-4 configuration, and the rest are trans-, 1,2- and 3,4- added isomers. It is absolutely free of proteins and phospholipids, but due to the absence of the almost $100 \%$ of cis-1-4 
configuration it commonly shows little strain crystallization with consequent lower green strength and hence lower mechanical properties.

Gregg and Macey have demonstrated that the insoluble non-rubber constituents in NR also account for the differences in properties between compounded NR and $\mathbb{I R}^{9}$. These nonrubber materials, mostly proteins, are responsible for the higher modulus, faster scorch time and higher tear strength of NR. The protein is postulated to act as a reinforcing filler at low concentrations (3-4 wt.\%) and as a cure activator. Othman and Hepburn have shown that the presence of proteins did not significantly affect the elastic modulus of a rubber vulcanizate ${ }^{4}$. However, the presence of its hydrolyzed constituents, amino acids, gave a marked increase in the modulus of vulcanizates.

The green strength of NR has always been ascribed to originate from proteins in NR. On the other hand, the removal of proteins in NR through deproteinization gives green properties similar to $\mathrm{NR}^{5,10}$; the removal of both proteins and phospholipids in $\mathrm{NR}$ by combined deproteinization and transesterification results in rubber with green strength comparable to that of $\mathrm{IR}^{10-12}$. Conversely, a simple addition of extracted proteins and/or phospholipids to the treated NR (after deproteinization and lipase treatment), did not improve the tensile properties, as it is not sufficient to revive the naturally occurring network in $\mathrm{NR}^{7}$. Consequently, the superior stress-strain behavior and the strain-induced crystallization of NR in both unvulcanized and vulcanized form must be from its characteristic network structure, which originates from the bonding of proteins and phospholipids with the terminal chain ends of the natural polyisoprene ${ }^{7}$. In a synchrotron x-ray study, the difference in the strength and strain-induced crystallization of vulcanized NR and IR is reported to originate from the pseudo or naturally occurring network ${ }^{13}$.

The thermal history and in particular the mixing dump temperature has been shown to be the parameter of paramount importance in mixing silica and rubber in presence of TESPT 
as coupling agent ${ }^{14-15}$. Wolff has reported that temperature has a more dominant effect than time in the silica-TESPT reaction ${ }^{16}$. In order to achieve a sufficient degree of silanization, the temperature during mixing should be between 150 and $160^{\circ} \mathrm{C}$. However, above $160^{\circ} \mathrm{C}$ either the coupling agent starts to prematurely react with the rubber matrix or the TESPT starts to donate sulfur; both result in pre-scorch of the compound. Reuvekamp et al. demonstrated that a mixing time of at least 10 minutes at $150^{\circ} \mathrm{C}$ is necessary to ensure complete coupling of the silica and the silane, and that the reaction between the silica and the silane takes place primarily during the first mixing step $^{14}$.

In the present work, the influence of mixing dump temperature on properties of silica reinforced NR is investigated. The effect of non-rubber constituents, particularly proteins, on silica reinforcement is highlighted in the presence and absence of coupling agent. NR is compared with purified NR from deproteinization (DPNR) as well as with synthetic polyisoprene (IR).

\section{EXPERIMENTAL SECTION}

\section{MATERIALS}

Standard Malaysian Natural Rubber (SMR20) and Deproteinized Natural Rubber (Pureprena) were provided by the Malaysian Rubber Board. The nitrogen contents of SMR20 and Pureprena are 0.2 and 0.07 respectively. It is generally accepted that the conversion factor from nitrogen content to protein content is $6.25^{4,17}$. Synthetic polyisoprene ( Nipol IR 2200, 98\% cis- 1,4 content, $82 \mathrm{MU}, \mathrm{ML}[1+4] @ 100^{\circ} \mathrm{C}$ ) was supplied by Zeon Corporation, Japan. Highly dispersible silica, Ultrasil 7005 with CTAB surface area of $164 \mathrm{~m}^{2} / \mathrm{g}$, and silane coupling agent, bis(triethoxysilylpropyl) tetrasulfide (TESPT), from Evonik were used. The compounding ingredients were treated distillate aromatic extract or TDAE oil (Vivatec 500, Hansen \& Rosenthal, Germany), zinc oxide (Sigma Aldrich), stearic acid (Sigma Aldrich), 
2,2,4-trimethyl-1,2-dihydroquinoline or TMQ (Flexsys, Belgium), sulfur (Sigma Aldrich), Ncyclohexyl-2-benzothiazyl sulfenamide or CBS (Flexsys, Belgium) and diphenyl guanidine or DPG (Flexsys, Belgium). All the ingredients were used as obtained from the respective sources. The compound formulation is based on a typical carbon black based truck tire tread recipe with the black replaced by silica as shown in Table I.

\section{SAMPLE PREPARATION}

The compounds were mixed in 2 steps. The first step was done using a laboratory internal mixer Brabender Plasticoder 350S lab station with a capacity of $390 \mathrm{ml}$. The fill factor of the mixer was fixed at $70 \%$ and the rotor speed used was $60 \mathrm{rpm}$. The starting temperature of the mixing chamber and rotor was varied from 70 to $120^{\circ} \mathrm{C}$ in order to obtain variable temperature histories and dump temperatures. A typical fingerprint of masterbatch mixing indicating the dump temperature is represented in Figure 2. After mixing for 14 minutes, the batches were sheeted out on a Schwabenthan $100 \mathrm{ml}$ two-roll mill, with a tight nip with 10 passes to improve the dispersion of silica. After 24 hours, the curatives were mixed on the luke-warm two-roll mill in the second step.

\section{SAMPLE ANALYSIS}

Mooney viscosity was measured at $100^{\circ} \mathrm{C}$ with a Mooney viscometer $2000 \mathrm{E}$ (Alpha Technologies) using the large rotor $(\operatorname{ML}(1+4))$ for compounds and the small rotor for the masterbatches $(\mathrm{MS}(2+4))$. Vulcanization curves were measured using a Rubber Process Analyzer (RPA 2000) from Alpha Technologies, under conditions of $0.833 \mathrm{~Hz}$ and $2.79 \%$ strain over a period of 30 minutes at a temperature of $150^{\circ} \mathrm{C}$. The Payne effect was measured prior and after cure in the RPA 2000 as well. Before cure the sample was heated to $100^{\circ} \mathrm{C}$ in the RPA and subsequently subjected to a strain sweep at $0.5 \mathrm{~Hz}$. The Payne effect was calculated as the difference between the storage modulus, $G^{\prime}$ at $0.56 \%$ and $G^{\prime}$ at $100.04 \%$ 
strain. The Payne effect after cure was measured after vulcanization in the RPA 2000 at $150^{\circ} \mathrm{C}$ for 10 minutes and subsequent cooling to $100^{\circ} \mathrm{C}$, making use of the same strain sweep conditions.

Wolff's filler structure parameter, $\alpha_{f}$ was determined from the ratio between the increase in vulcameter torque of the filled compounds and that of the unfilled gum ${ }^{18}$ :

$$
\frac{D_{\max }-D_{\min }}{D_{\max }^{o}-D_{\min }^{o}}-1=\alpha_{f} \frac{m_{f}}{m_{p}}
$$

eq.1

Where $D_{\max }-D_{\min } \quad$ is the maximum change in torque for the filled rubber, $D^{o}{ }_{\max }-D^{o}{ }_{\min }$ is the maximum change in torque for the unfilled gum rubber, $m_{f} / m_{p}$ is the weight ratio of filler to polymer, $\alpha_{f}$ is a filler specific constant which is independent of the cure system and closely related to the morphology of the filler.

The bound rubber content (BRC) measurements were performed on unvulcanized samples by extracting the unbound rubber with toluene at room temperature for seven days in both normal and ammonia environment. The ammonia treatment of BRC was done to obtain the chemically bound rubber as ammonia cleaves the physical linkages between rubber and silica $^{19-20}$. The amount of BRC ( $\mathrm{g} / \mathrm{g}$ filler) was calculated by:

$$
B R C(g / g \text { filler })=\frac{w_{d r y}-w_{\text {insol }}}{w_{o} \times \frac{w_{\text {fillerphr }}}{w_{\text {totalphr }}}} \quad \text { eq.2 }
$$

Where $\mathrm{w}_{\mathrm{o}}$ is the initial weight of the sample, $\mathrm{w}_{\mathrm{dry}}$ is the dry weight of the extracted sample, $\mathrm{w}_{\mathrm{insol}}$ is the weight of insolubles (mainly filler) in the sample, $\mathrm{w}_{\text {filler,phr }}$ is the total filler weight in phr and $\mathrm{w}_{\text {total, phr }}$ is the total compound weight in phr. The physically BRC was taken as the difference between untreated BRC and ammonia treated BRC.

Vulcanizates were prepared by curing the compounds for their respective t95 $_{95}$ (time to reach $95 \%$ of torque difference in the curemeter) at $150^{\circ} \mathrm{C}$ using a Wickert laboratory press 
WLP $1600 / 5 * 4 / 3$ at 100 bar. Tensile properties of the vulcanizates were measured using a Zwick Z020 tensile tester according to ISO-37. The hardness of the cured samples was determined according to DIN-53505. The tan delta (G'/G') at $60^{\circ} \mathrm{C}$ was measured using the RPA 2000 by applying a frequency sweep at $3.49 \%$ strain after first curing in the RPA at $150^{\circ} \mathrm{C}$.

\section{RESULTS AND DISCUSSION}

\section{COMPOUND PROCESSABILITY}

In terms of processability of the masterbatches, NR and DPNR are comparable, but IR shows completely different behavior with lower viscosity. In Figure 3, the increase in viscosity of the masterbatches of NR and DPNR with rising mixer dump temperature up to a temperature of $150^{\circ} \mathrm{C}$ is a combination of the hydrodynamic effect and silanization rate of the silica. More silica is hydrophobized by TESPT when the dump temperature is raised, and this results in a higher compatibility between silica and rubber and consequently increment of the viscosity. Oppositely, in the case of synthetic polyisoprene IR, the Mooney viscosity is not affected by a dump temperature below $150^{\circ} \mathrm{C}$. This demonstrates the different behavior of synthetic rubber as compared to NR as also reported by Kaewsakul and coworkers ${ }^{15}$. With increasing dump temperature, the silanization of silica in the IR masterbatch also increases but molecular motion of the rubber chain is not restricted. It is interesting to see that the viscosity of all masterbatches decreases above their respective optimum dump temperatures. One possible explanation is the molecular chain scission of NR at higher temperatures during mixing, which may even be more pronounced in its synthetic equivalent IR. This thermomechanical degradation of NR and IR results in reduction of their molecular weights and hence lower viscosities. 
Once the curatives are added to the compounds, the viscosities of NR and DPNR drop to acceptable levels, mainly due to the remilling step. For the NR compounds, the Mooney viscosity is seen to increase with increasing dump temperature up till $150^{\circ} \mathrm{C}$ and becomes constant afterwards. For the DPNR compounds, a linear increase in Mooney viscosity is observed with increasing dump temperature to a maximum of $160^{\circ} \mathrm{C}$, and the values are also higher than those of NR. However, the IR compound now exhibits higher Mooney viscosities, almost double of those of NR. In addition, the IR compound shows a clear optimum in viscosity at dump temperature of $150^{\circ} \mathrm{C}$. The decrease in Mooney viscosity for IR above dump temperature $150^{\circ} \mathrm{C}$ suggests that silica is being further hydrophobized by silane after the second stage of mixing.

\section{EFFECT OF SILANE TESPT ON FILLER FLOCCULATION}

Without silane coupling agent, silica develops strong networking in the compounds. A high initial torque rise leading to a two-step vulcanization curve is observed in all NR-, DPNR- and IR-silica compounds without silane as illustrated in Figure 4(a). The initial torque rise at the beginning of the vulcanization is commonly associated with re-agglomeration or flocculation of silica in the compounds ${ }^{21-22}$. The NR compound has a shorter scorch time than the DPNR compound. On the other hand, the IR compound indicates a scorch problem: practically no scorch time at the vulcanization temperature employed. The use of silane TESPT in the silica compound results in far less pronounced silica flocculation as demonstrated by only a small initial torque rise at the beginning of vulcanization: Figure 4(b). As compared to the silica compounds without silane, the flocculation tendency of silica in the compounds with TESPT is small due to hydrophobation of the silica surface by TESPT. It is noted that the scorch safety of NR and IR also improves with the use of TESPT. 


\section{VULCANIZATION PROPERTIES}

The influence of the mixing temperature history, in particular the dump temperature of the first mixing step on the vulcanization behavior of the NR-silica-TESPT compounds as compared to the DPNR-silica-TESPT and IR-silica-TESPT compounds is illustrated in Figures $5-7$, respectively. The vulcanization behavior of the compounds can be divided into three groups according to dump temperature. The first one encompasses the compounds with low dump temperatures (below $150^{\circ} \mathrm{C}$ ), which exhibit pronounced flocculation as evidenced by initial torque rise, high maximum torques and long scorch times. The middle group is represented by the vulcanization curves of the compounds with dump temperatures around 150 to $155^{\circ} \mathrm{C}$, which show no appearance of flocculation, lower maximum torques and shorter scorch times as compared to those of the compounds with low dump temperature. The vulcanization curves of the third group, the compounds with high dump temperatures $\left(>155^{\circ} \mathrm{C}\right)$ display a lower maximum torque and no sign of flocculation. At high mixing temperature, the silanization reaction increases and results in a reduction of silica-silica interaction. However, in the vulcanization curves for these high dump temperatures, there is also clear indication of reversion.

The effect of mixing temperature history on vulcanization behavior of the DPNRsilica compound is smaller than for the NR-silica compound. Silica flocculation occurs in the DPNR compound mixed with lowest dump temperature, as also in NR. The maximum torque of the DPNR compound mixed at moderate temperature of around $150^{\circ} \mathrm{C}$ is comparable with the NR compound. Nonetheless, the decrease in maximum torque for the DPNR compound at higher dump temperature is much less compared to the NR-silica compound. The low protein content in DPNR may attribute to better silanization in the compound which gives more filler to rubber linkages. The DPNR-silica compounds with high dump temperature also show no 
sign of reversion as seen in NR compounds. This suggests that a different network structure in the DPNR contributes to the thermal resistance of the cured compound.

In Figure 7, the influence of dump temperature is most pronounced for the IR-silicaTESPT compound. The increase in dump temperature reduces the maximum torque of the IR compound very significantly. The vulcanization curves resemble those for NR-silica-TESPT most closely, where the various phenomena are even more pronounced.

\section{INFLUENCE OF SILANE TESPT ON PAYNE EFFECT}

Filler-filler interaction is commonly measured by the so-called Payne effect: the drop in storage modulus in a dynamic mechanical test when the strain (deformation) is increased from low $(0.56 \%)$ to a high value $(100 \%)$ at constant frequency and temperature. The storage modulus of filled rubber drastically decreases as strain increases as the result of breakage of physical bonds between filler particles, for example van der Waals, hydrogen bonds and London forces.

The use of silica without silane modification in rubber, mixed till $160^{\circ} \mathrm{C}$ dump temperature, results in a high Payne effect due to strong interaggregate interaction of silica as shown in Figure 8. This relates well with the marked flocculation signs in the vulcanization curves of the silica compounds without silane. With TESPT modification, the Payne effect of the silica-filled compounds is greatly reduced As more silica surface is hydrophobized by TESPT, the silica-silica network is disrupted. The Payne effect for compounds with silane is observed to decrease in the order of NR>DPNR $>$ IR. This points to a relation between the amount of protein and the increase of silica-silica interaction. In other words, it indicates that the hydrophobation of the silica surface by silane is indeed partially hindered due to silicaprotein interactions.

The use of TESPT in silica-filled NR, DPNR and IR also results in higher modulus, G' at high strains as compared to the compounds without silane, as illustrated in Figure 8 . The 
values of the G' at high strain for all three rubbers do not differ much. This phenomenon is described by Luginsland et al. as the formation of in-rubber structure ${ }^{23}$. The chemical linkages formed by silica-TESPT-rubber coupling result in the immobilization of rubber on the silica surface and within its structure.

A more detailed comparison of filler-filler interaction in NR-silica-TESPT compounds with DPNR-silica-TESPT and IR-silica-TESPT compounds as a function of mixing temperature is shown in Figure 9. The Payne effect of all silica-TESPT compounds decreases sharply with increasing dump temperature, as is also seen in synthetic rubber / silica compounds and taken as a sign of reaction and consequent hydrophobation of the silica by the silane coupling agent ${ }^{14-15}$. Before vulcanization, the Payne effect for IR compounds is surprisingly higher as compared to the NR-silica and DPNR-silica compounds. In contrast, after vulcanization, the Payne effect of the IR compound is lower than for the NR- and DPNR-compounds throughout the variation of dump temperature. This indicates that the silanization of silica in IR proceeds slower during mixing than in NR, but is more than compensated after vulcanization.

\section{RUBBER-TO-FILLER INTERACTIONS}

Figure 10 illustrates the effect of mixing temperature on Wolff's filler structure parameter, $\alpha_{f}$. As observed earlier with the Payne effect, $\alpha_{f}$ is reduced with increasing dump temperature for the NR, DPNR and IR compounds. Better hydrophobation leads to a decrease in silica-silica interaction and consequently results in reduced $\alpha_{f}$. The DPNR compound shows a higher $\alpha_{f}$ than the NR compound, indicating a different type of filler and rubber network in the two compounds. For the synthetic IR compound, the $\alpha_{f}$ is smaller than for NR. This corresponds with their Payne effects after vulcanization as shown earlier.

The filler to rubber interaction of silica-filled NR with varying protein content can also be judged on basis of the chemically and physically bound rubber content as illustrated in 
Figure 11. The chemically bound rubber of the silica-TESPT compound increases with increasing dump temperature up to $150^{\circ} \mathrm{C}$. This can be explained by the higher rate of silanization with increasing mixing temperature. However, at $150^{\circ} \mathrm{C}$, there is saturation in the amount of TESPT which has reacted and the surface of silica covered. Precipitated silica has about 4 to 5 silanol groups per $\mathrm{nm}^{2}$. Hence, there is no increase in chemically bound rubber for compounds mixed till above $150^{\circ} \mathrm{C}$ dump temperature. Above $150^{\circ} \mathrm{C}$, the chemically bound rubber slowly decreases for NR and DPNR, while for IR it stabilizes. In comparison, DPNR has more chemically bound rubber than NR, particularly at high dump temperature. Meanwhile, the IR compounds exhibit a considerably lower chemically bound rubber as compared to the NR and DPNR compounds. This is due to the slower rate of silanization in IR, as could also be taken from the results of the Payne effect before vulcanization above. Hence, the rubber to filler interaction is also reduced.

In Figure 11(b), the small increase in the physically bound rubber of the NR-silica and DPNR-silica compounds containing TESPT at higher dump temperature can be explained by the saturation of silica-TESPT coupling. Additional interactions above $150^{\circ} \mathrm{C}$ between the non-hydrophobized silica surfaces and rubber are physical of nature. The IR compound shows a more constant physically bound rubber which is comparable to that of NR. It is suggested as a result of physical adsorption and also the occluded rubber in silica-silica network for IR. As discussed above in the Payne effect, the in-rubber structure of IR-silica containing TESPT is comparable to those of NR and DPNR. The in-rubber structure includes the immobilization of rubber on the surface of silica due to silane modification, whether it is chemical or physical of nature and the occluded rubber in the silica network. With ammonia treatment, the immobilization of physically bound rubber in the silica structure or occluded rubber is released since physical interactions like the hydrogen bonding are destroyed. 


\section{MECHANICAL AND DYNAMIC PROPERTIES}

The use of TESPT as a coupling agent improves the stress-strain properties of silicafilled compounds. In Figure 12, it can be seen that NR-, DPNR- and IR-vulcanizates without silane exhibit inferior stress-strain behavior than those with silane. In comparison, the DPNR vulcanizates perform better than NR and IR in the presence and absence of coupling agent.

The effect of dump temperature on the physical properties of silica vulcanizates is depicted in Figure 13. At dump temperatures above $150^{\circ} \mathrm{C}$, both $\mathrm{NR}$ and IR vulcanizates show a clear reduction in tensile strength and the effect is most pronounced in the case of IR. This shows that mixing temperature is of importance for the NR-silica compounds. However, this reduction in tensile strength at high dump temperature is not seen for the low protein DPNRsilica vulcanizates. For the IR vulcanizate, the tensile strength is inferior to NR and DPNR vulcanizates. The elongation at break for the NR and DPNR vulcanizates reduces slightly with increasing dump temperature. The IR vulcanizates show a higher elongation at break as compared to NR and DPNR but are observed to decrease with mixing dump temperature as well.

A decrease in both moduli at 300\% elongation (M300) and 100\% elongation (M100) at higher dump temperatures is seen for the NR and IR vulcanizates. In contrast, DPNR vulcanizates exhibit higher moduli with the increasing mixing dump temperature. The reduction in the tensile properties of NR and IR at high mixing temperature is in good agreement with the occurrence of reversion and decrease in the maximum torque observed in their vulcanization curves. In contrast, reversion is not seen in the vulcanization curve of DPNR and the effect of dump temperature on torque difference is also smaller. Another possible reason for the better properties achieved for DPNR is the difference in the naturally occurring networking as compared to NR. Amnuaypornsri et al. ${ }^{24}$ have proposed that the network structure of purified DPNR is associated with phospholipids linking both terminal 
end groups of the rubber chain via hydrogen bonding and ionic linkages, while the proteins bonds are released because of deproteinization.

Both NR-silica and DPNR-silica have a superior reinforcement index M300/M100 as compared to IR-silica vulcanizates as shown in Figure 14. With increasing mixing temperature, the reinforcement index of the NR and IR vulcanizates is somewhat improved. The processing conditions have less influence on the reinforcement index of DPNR. A better reinforcement index is obtained with higher chemically bound rubber of the compound as illustrated in Figure 14 (b). It indicates that the improvement in properties is related to the increase in rubber to filler interaction.

Commonly, the loss $\tan \delta$ at $60^{\circ} \mathrm{C}$ of a cured compound is employed as indication for the rolling resistance of tires made thereof. The lower $\tan \delta$ at $60^{\circ} \mathrm{C}$, the lower the rolling resistance expected in real tire performance. Figure 15 illustrates indications of rolling resistance of the silica-filled vulcanizates. Both NR and DPNR vulcanizates show a strong decrease in $\tan \delta$ at $60^{\circ} \mathrm{C}$ with increasing dump temperature. This must obviously be the result of more coupling of silica to the rubber with greater silanization efficiency at high temperatures. IR also shows a reduction in $\tan \delta$ at $60^{\circ} \mathrm{C}$ with increasing dump temperature, but only up to $150^{\circ} \mathrm{C}$. Above a dump temperature of $150^{\circ} \mathrm{C}$, the $\tan \delta$ at $60^{\circ} \mathrm{C}$ of the IR vulcanizates shows a marked increase. The DPNR vulcanizates exhibit the lowest $\tan \delta$ at $60^{\circ} \mathrm{C}$ at high dump temperature. This actually relates well with the higher chemically bound rubber content of DPNR compared to the NR compound.

In general, DPNR shows better mechanical and dynamic properties as compared to NR. In contrast, IR performs overall much worse, particularly if mixed till high dump temperature.

This paper illustrates in a phenomenological manner the reinforcement of various polyisoprenes by the silica-silane system. The results show the complicated nature of NR and 
that its influence on the mechanism of reinforcement is still unsatisfactorily understood. In addition to the chemical bonds between silica and rubber, the reinforcement of NR by silica fillers is also strongly governed by the polymer properties itself. NR is a unique natural product, subject to seasonal variations, and containing non-rubber constituents, such as proteins and phospholipids, and this makes this material very complex. The absence of these non-rubber constituents, in the case of IR, and removal of proteins, in the case of DPNR, show completely different behavior compared to NR even though they have nearly the same polyisoprene microstructure: till the last few percents poly(cis 1,4-isoprene). How far the proteins and phospholipids affect the reinforcement of NR still needs further elucidation. Reinforcement of NR with silica remains a challenge but it offers tremendous potential as a source of renewable energy.

\section{CONCLUSIONS}

The key element in the reinforcement of rubber by silica is the chemical coupling between silica and rubber, which applies for both synthetic and natural rubbers. The investigation has demonstrated that the temperature development is an important parameter in mixing silica and natural and synthetic poly (cis 1,4-isoprene) with the aid of TESPT as coupling agent in order to achieve proper silanization of silica. Silica-silica interaction is reduced with hydrophobation of the silica surface by TESPT through silanization at sufficiently high mixing temperatures. In NR compounds, the silanization reaction between silica and TESPT progresses with increasing mixing dump temperature, which can be monitored with the drop in Payne effect of the compounds. Above an optimum dump temperature of approximately $150^{\circ} \mathrm{C}$, NR suffers in loss of dynamic and mechanical properties due to thermo-mechanical degradation. This effect is even more pronounced in the case of its synthetic equivalent: IR. On the other hand, removal of proteins from NR, in this 
case DPNR, results in a smaller influence of dump temperature and more constant mechanical properties. Dynamic properties improve with the silica-silane-rubber coupling as evidenced by a lower $\tan \delta$ at $60^{\circ} \mathrm{C}$ obtained especially in DPNR-silica-TESPT compounds.

\section{ACKNOWLEDGEMENTS}

The authors would like to express gratitude for financial support from the Malaysian Rubber Board, Malaysia for this project.

\section{REFERENCES}

${ }^{1}$ W. Meon, A. Blume, H-D. Luginsland, and S. Uhrlandt, in Rubber Compounding: Chemistry and Applications”, B. Rodgers, Ed., Marcel Dekker: New York, 2004, Chapter 7.

${ }^{2}$ J.W. Noordermeer and W.K. Dierkes, in "Rubber Technologist's Handbook", Vol.2, J.

White, S.K. De and K. Naskar, eds., Smithers Rapra Technology, Shawbury, Shrewsbury, Shropshire, UK, (2008), Chapter 3.

${ }^{3}$ S.S. Sarkawi, W.K. Dierkes and J.W.M. Noordermeer, EU-PEARLS 2010 Meeting: The Future of Natural Rubber, Montpellier, France (2010).

${ }^{4}$ A.B. Othman and C. Hepburn, Plast. Rub. Compos. Pro., 19, 185 (1993).

${ }^{5}$ Y. Tanaka and L. Tarachiwin, RUBBER CHEM. TECHNOL. 82, 283 (2009).

${ }^{6}$ J. Sakdapipanich, J. Biosci. Bioeng.103, 287-292 (2007).

${ }^{7}$ S. Amnuaypornsri, J. Sakdapipanich, S. Toki, B.S. Hsiao, N. Ichikawa and Y. Tanaka, RUBBER CHEM. TECHNOL. 81, 753 (2008).

${ }^{8}$ L. Tarachiwin, J. Sakdapipanich and Y. Tanaka, Kautsch. Gummi Kunstst., 58, 115 (2005).

${ }^{9}$ E.C. Gregg and J.H. Macey, RubBer ChEM. TeCHnOL. 46, 47 (1973).

${ }^{10}$ Y. Tanaka, RuBBER CHEM. TECHNOL. 74, 355 (2001).

${ }^{11}$ S. Kawahara, T. Kakubo, N. Nishiyama, Y. Tanaka, Y. Isono and J. Sakdapipanich, J. Appl. 
Polym. Sci. 78, 1510 (2000).

${ }^{12}$ S. Kawahara, Y. Isono, T. Kakubo, Y. Tanaka, and A.H. Eng, RuBBER CHEM. TECHNOL. 73, 39 (2000).

${ }^{13}$ S. Toki, J. Che, L. Rong, B.S. Hsiao, A. Nimpaiboon and J. Sakdapipanich, Fall 180th Technical Meeting, ACS Rubber Division, Cleveland, USA, paper no.9 (Oct. 2011).

${ }^{14}$ L.A.E.M. Reuvekamp, J.W. ten Brinke, P.J. van Swaaij and J.W.M. Noordermeer, RUBBER CHEM. TECHNOL. 75, 187 (2002).

${ }^{15}$ W.K. Kaewsakul, K. Sahakaro, W.K. Dierkes and J.W.M. Noordermeer, RUBBER CHEM. TECHNOL. 85, 277 (2012).

${ }^{16}$ S. Wolff, RUBBER CHEM. TECHNOL. 55, 967 (1982).

${ }^{17}$ M.J.R. Loadman and W.C. Wake, “Analysis of Rubber and Rubber-like Polymers”, Kluwer Academic Publishers, the Netherlands, p.96 (1988).

${ }^{18}$ S. Wolff, Kautsch. Gummi Kunstst. 23, 7(1970).

${ }^{19}$ K.E. Polmanteer and C.W. Lentz, RubBER CHEM. TECHNOL. 48, 795 (1975).

${ }^{20}$ S. Wolff, M.-J. Wang and E.-H. Tan, RUBBER CHEM. TECHNOL. 66, 163 (1992).

${ }^{21}$ C.J. Lin, W.L. Hergenrother, E. Alexanian and G.G.A. Bö hm, RUBBER CHEM. TECHNOL. 75, 865 (2002).

${ }^{22}$ S. Mihara, R.N. Datta and J.W.M. Noordermeer, RubBER CHEM. TECHNOL. 82, 524 (2009).

${ }^{23}$ H.-D. Luginsland, J. Fröhlich and A. Wehmeier, RuBBER CHEM. TECHNOL. 75, 563 (2002).

${ }^{24}$ S. Amnuaypornsri, L. Tarachiwan and J. Sakdapipanich, J. App. Polym. Sci. 115, 3645 (2010) 
TABLE I

COMPOUND FORMULATION

\begin{tabular}{lc}
\hline \multicolumn{1}{c}{ Ingredients } & Amount (phr) \\
\hline Natural Rubber (NR or DPNR or IR) & 100 \\
Silica Ultrasil 7005 & 55 \\
Silane, TESPT & 5 \\
Zinc Oxide & 2.5 \\
Stearic acid & 1 \\
TDAE oil & 8 \\
TMQ & 2 \\
Sulfur & 1.4 \\
CBS & 1.7 \\
DPG & 2 \\
\hline
\end{tabular}




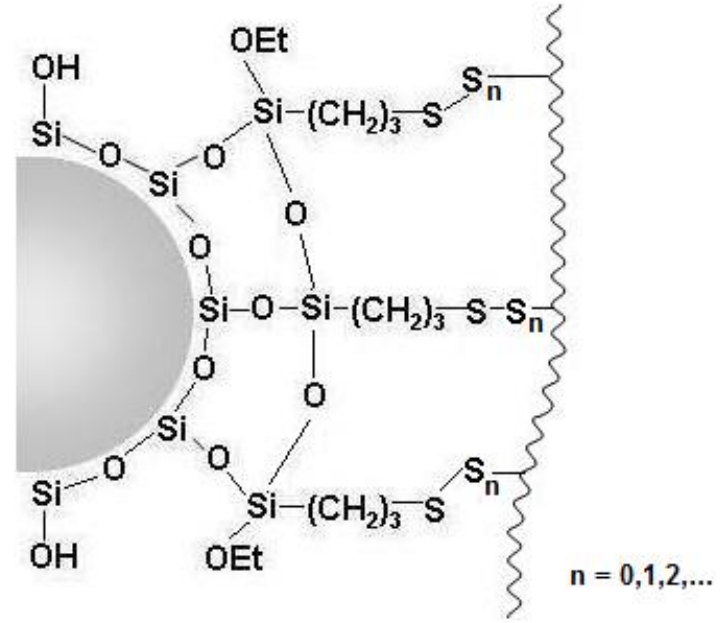

FIG. 1 - Silica-silane-rubber coupling. 


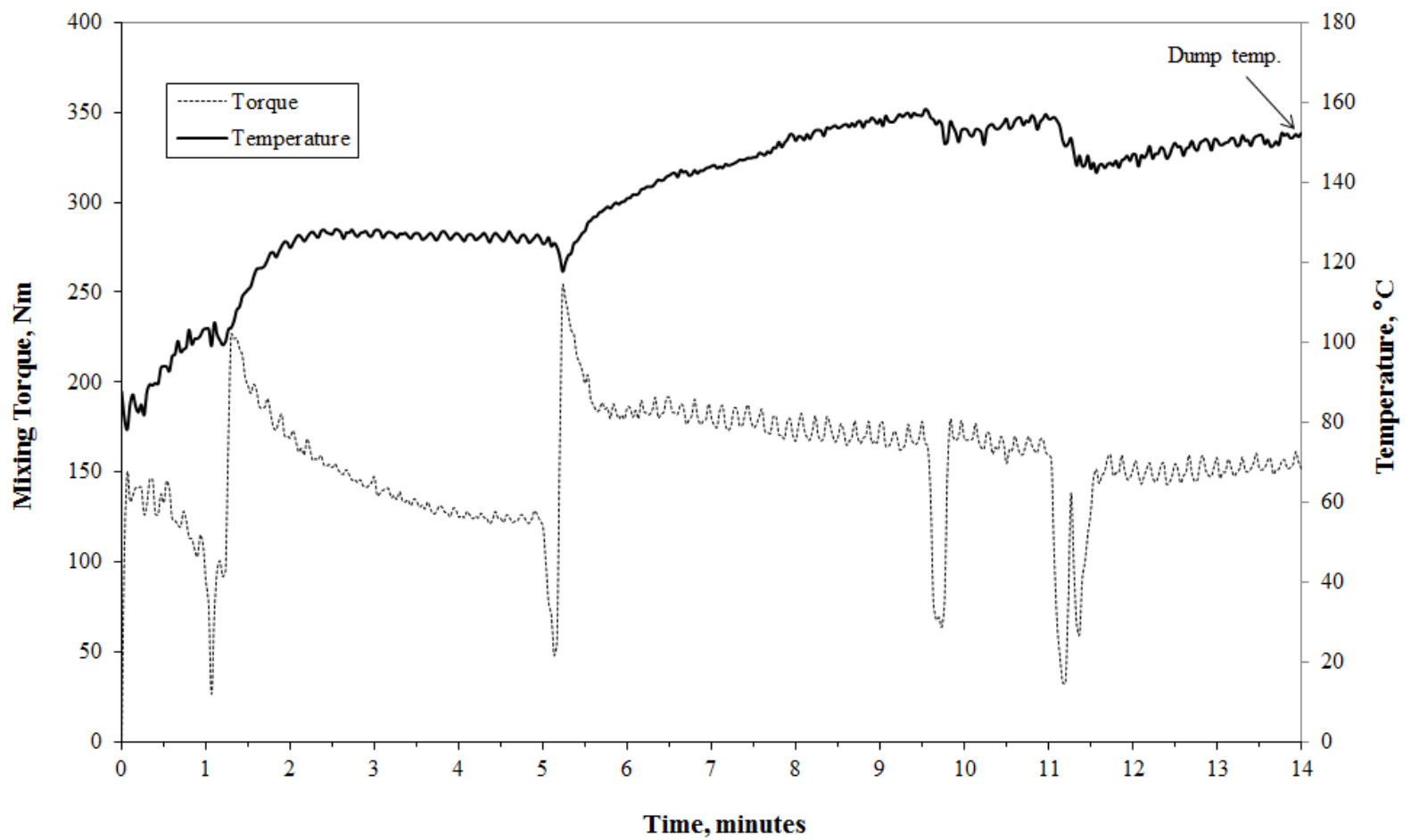

FIG. 2 - Typical fingerprint of the masterbatch mixing of the first mixing stage in the internal mixer showing the dump temperature. 

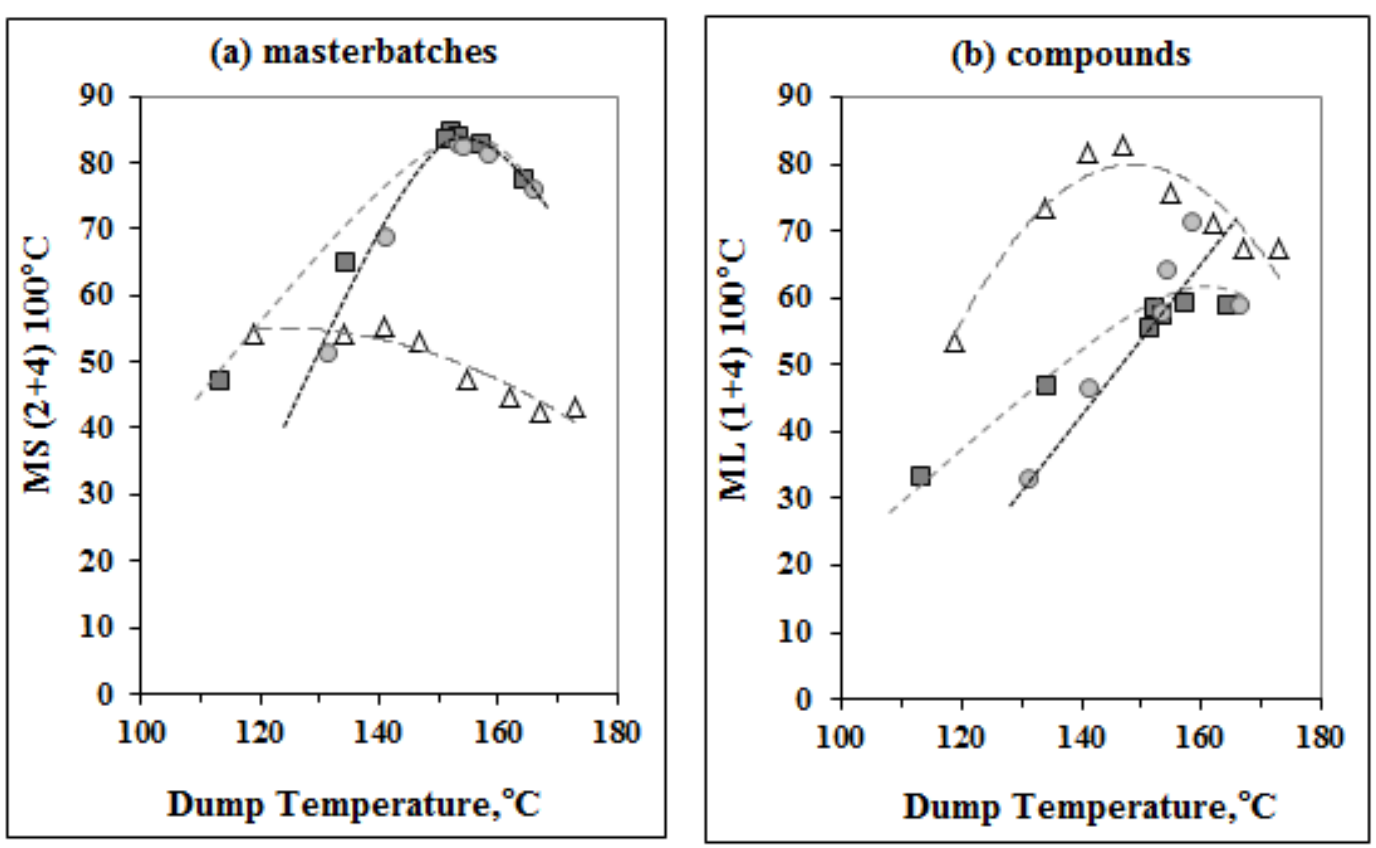

FIG. 3 - Mooney viscosities of : (a) masterbatches after $1^{\text {st }}$ mixing, and (b) compounds after $2^{\text {nd }}$ mill mixing of silica-filled compounds at varying dump temperature: $(\boldsymbol{\bullet})$ : NR; (•): DPNR; $(\Delta):$ IR. 
(a) Without silane

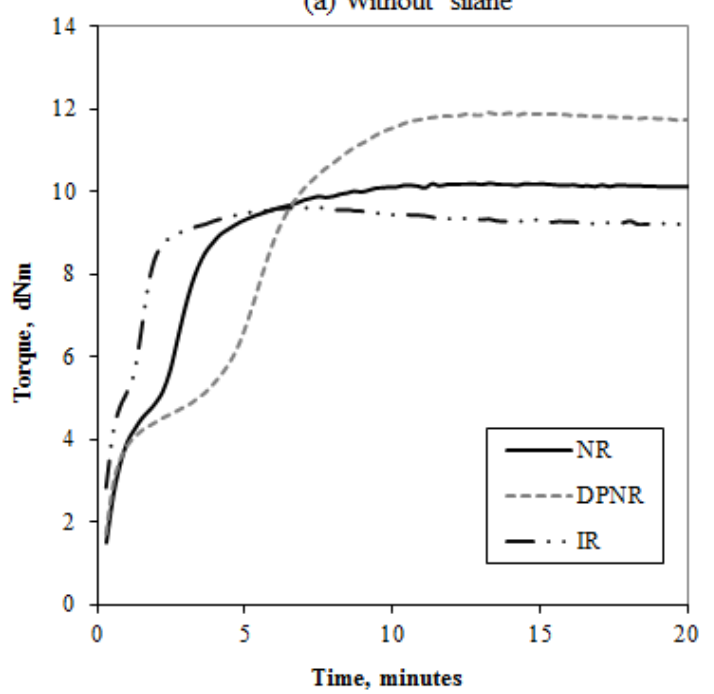

(b) With silane

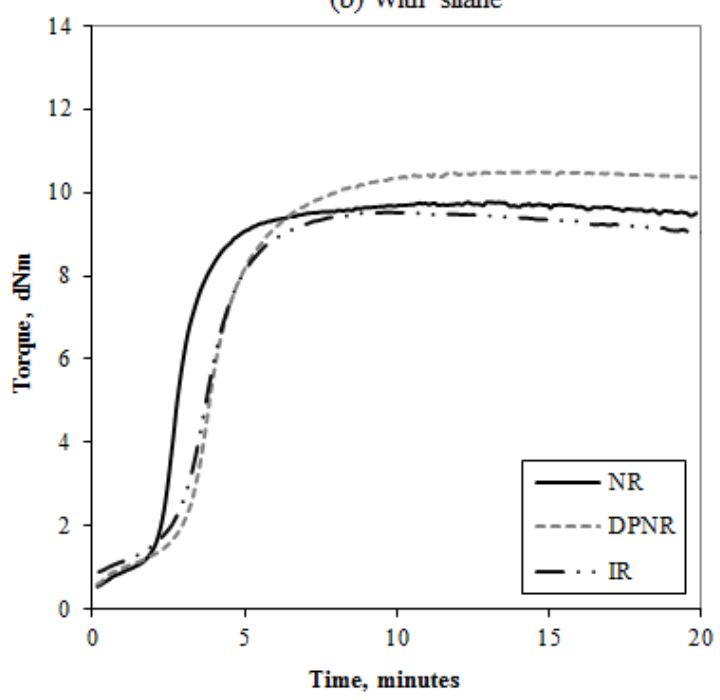

FIG. 4 - Comparison of vulcanization curves at $150^{\circ} \mathrm{C}$ of silica compounds: (a) with silane and (b) without silane. 


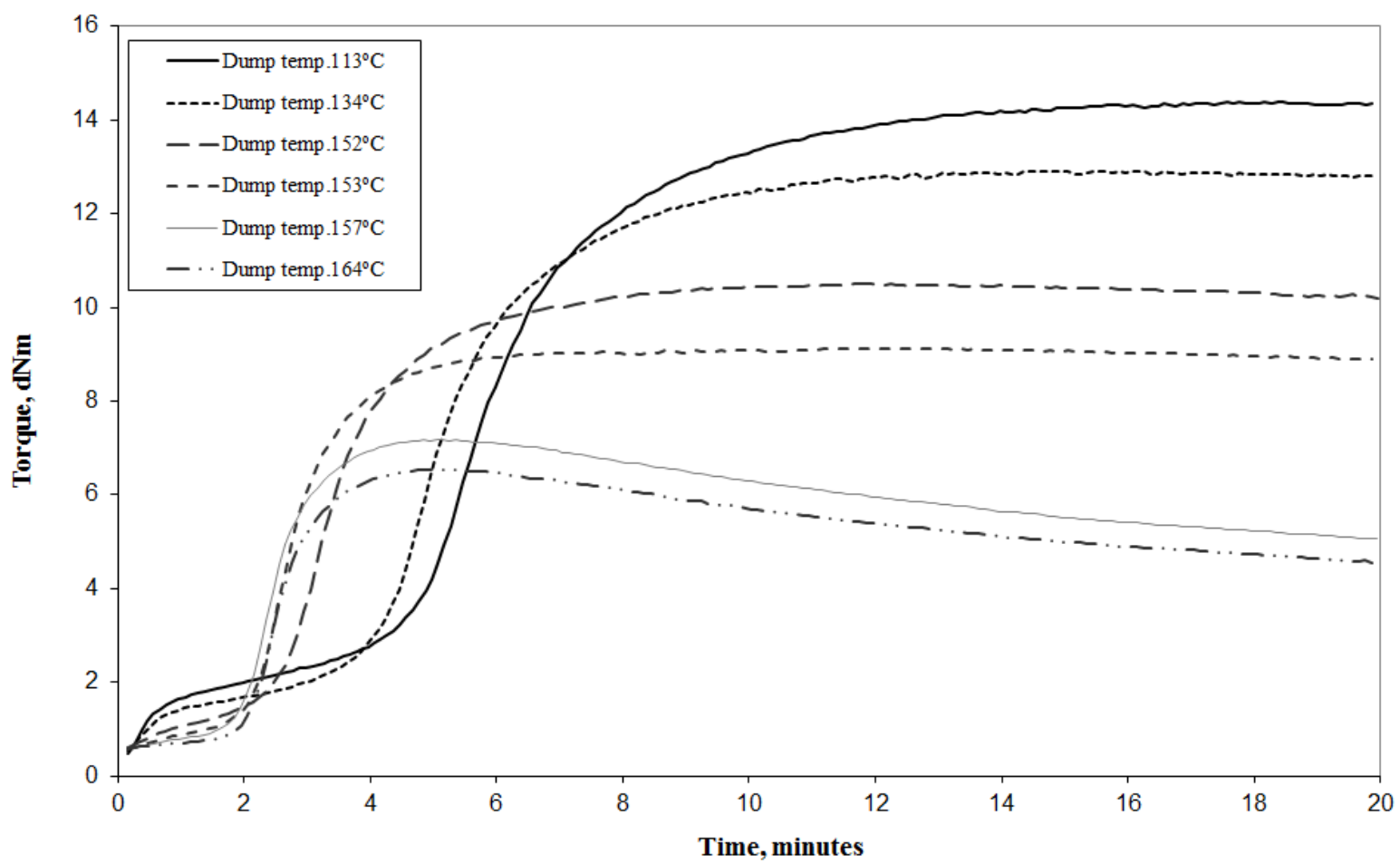

FIG. 5 - Vulcanization behavior at $150^{\circ} \mathrm{C}$ of the NR compound mixed till different dump temperatures in the first mixing stage. 


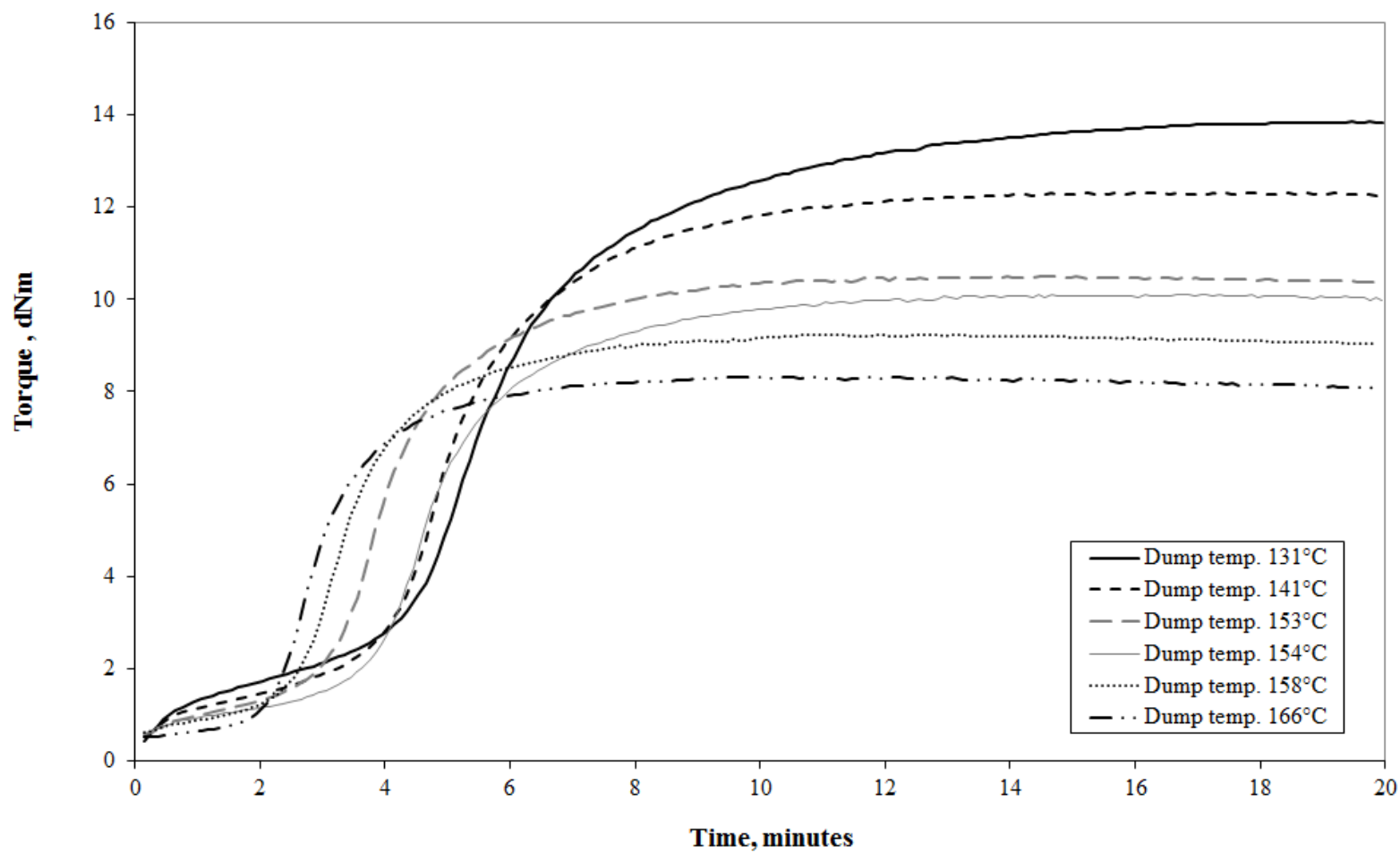

FIG. 6 - Vulcanization behavior at $150^{\circ} \mathrm{C}$ of the DPNR compound mixed till different dump temperatures in the first mixing stage. 


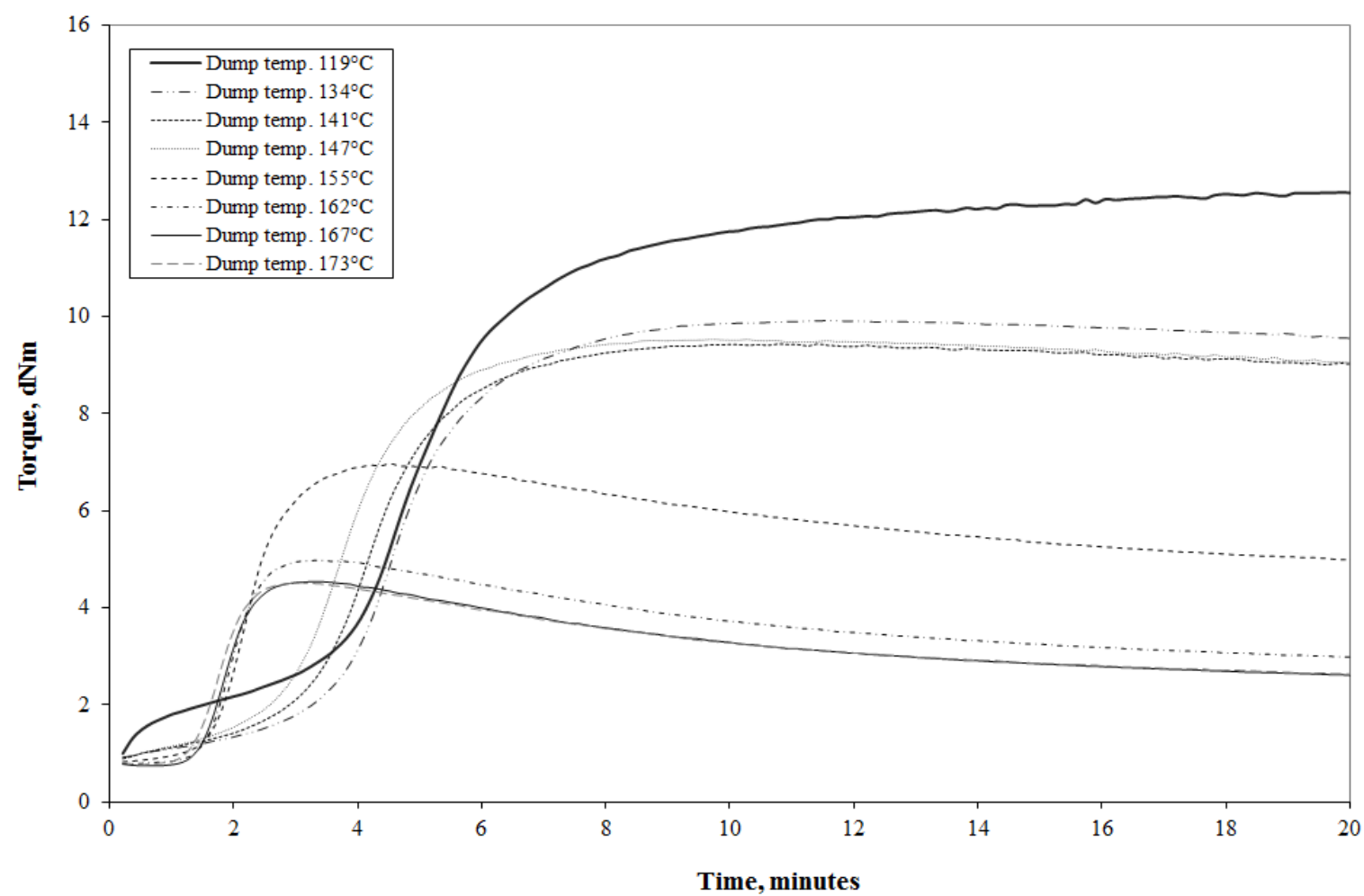

FIG. 7 - Vulcanization behavior at $150^{\circ} \mathrm{C}$ of the IR compound mixed till different dump temperatures in the first mixing stage. 


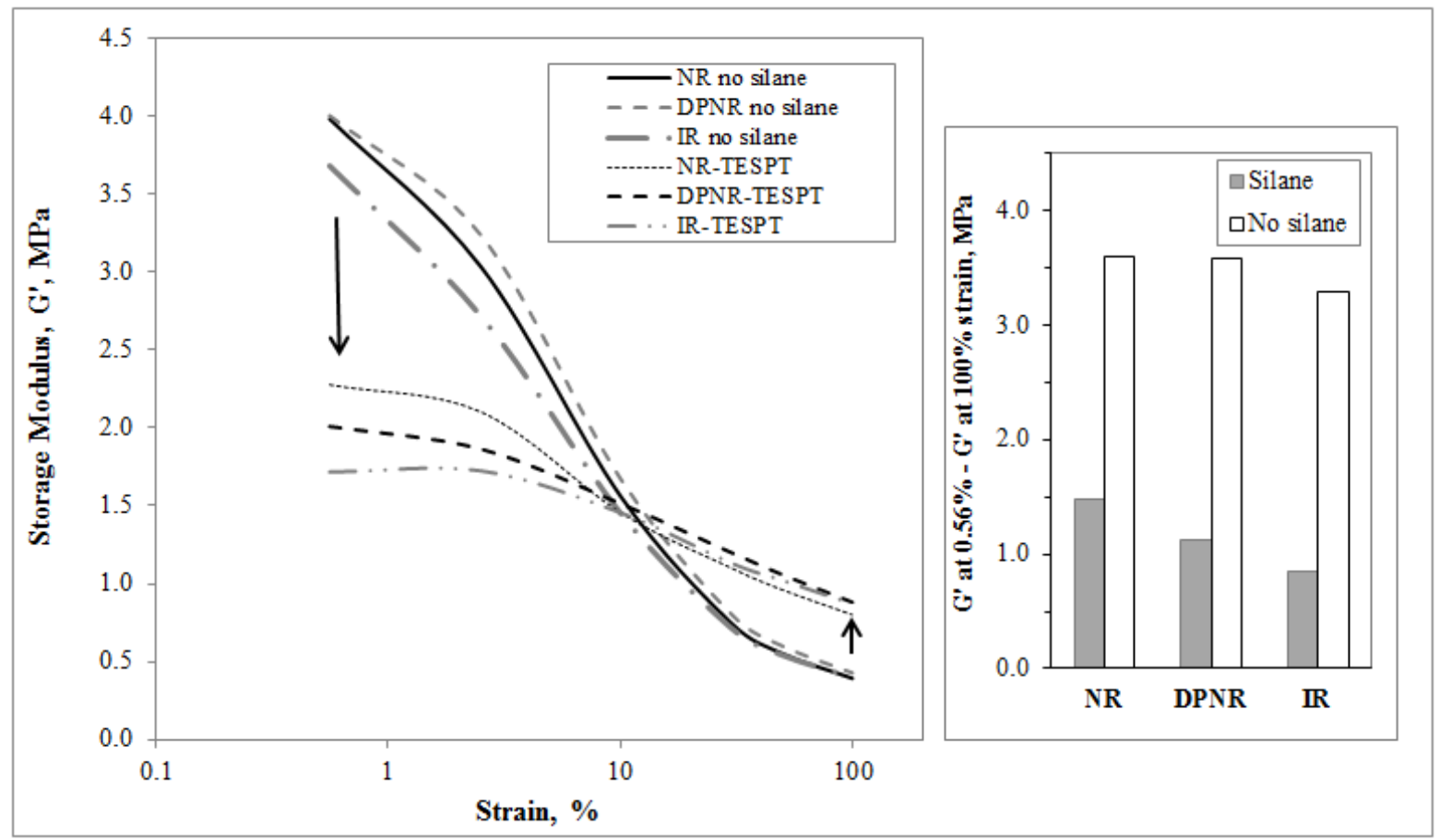

FIG. 8 - Comparison of Payne effect of silica compounds with silane and without silane 

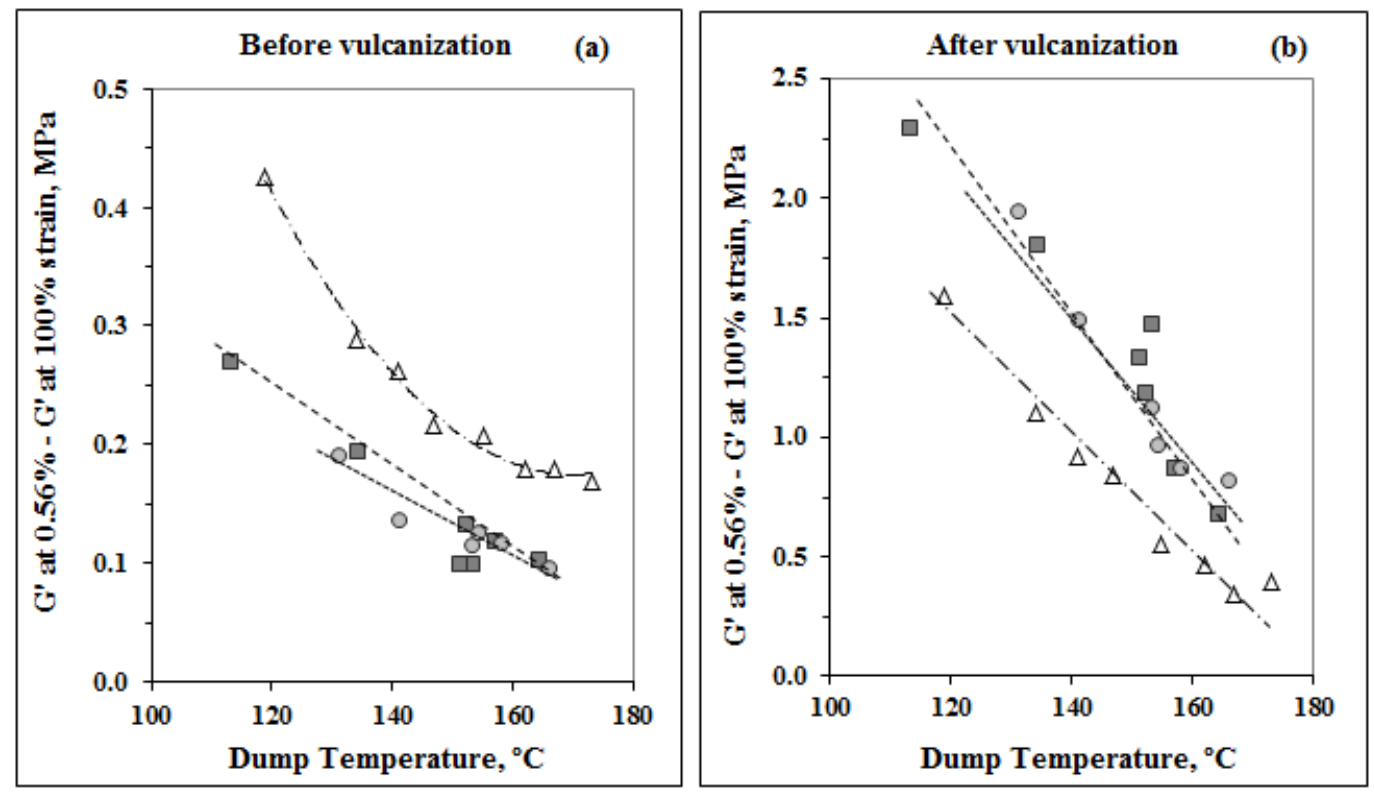

FIG. 9 - Payne effect of silica compounds with silane TESPT as a function of dump temperature: (a) unvulcanized samples; (b) vulcanized samples; (匹): NR; (•): DPNR;

$(\Delta):$ IR. 


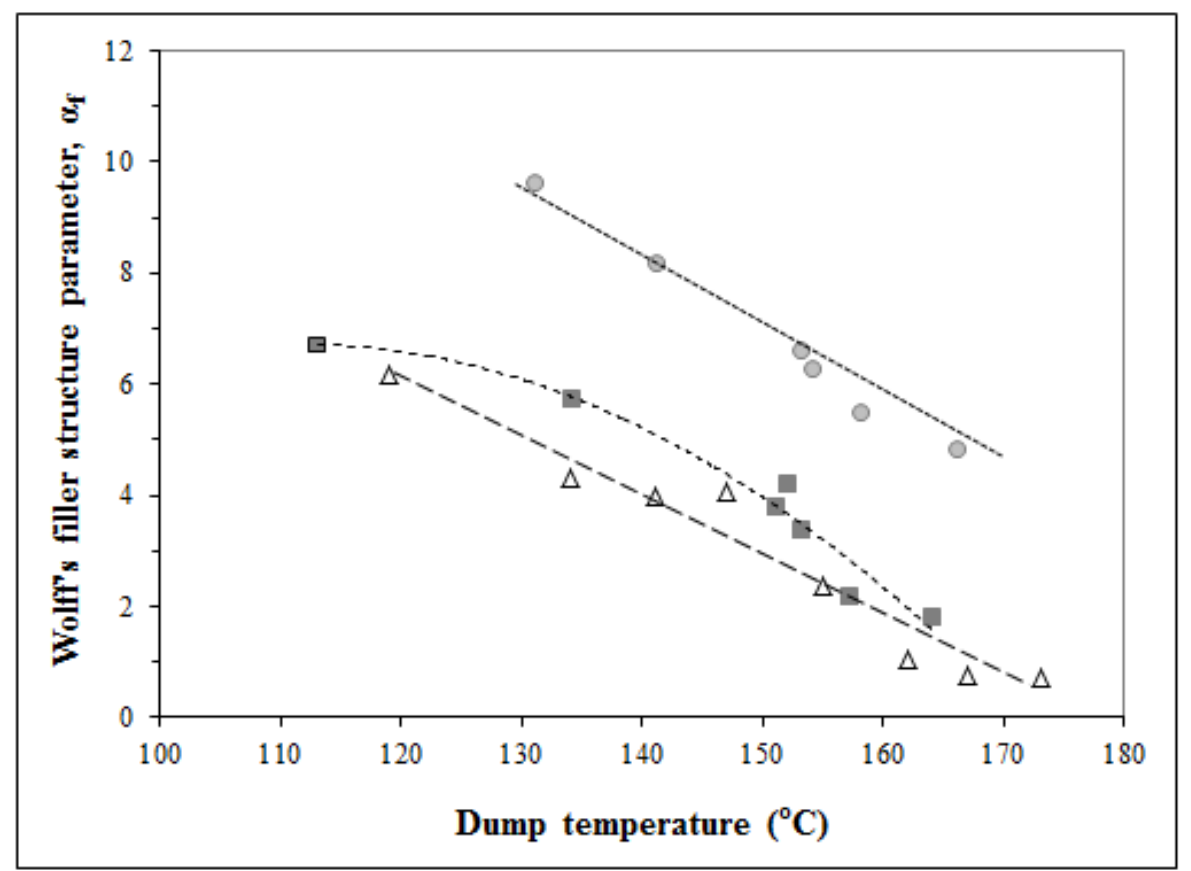

FIG. 10 - Effect of dump temperature on Wolff's filler structure parameter, $\alpha_{f}$ of silica reinforced compounds: (匹): NR; (•): DPNR; $(\Delta)$ : IR. 

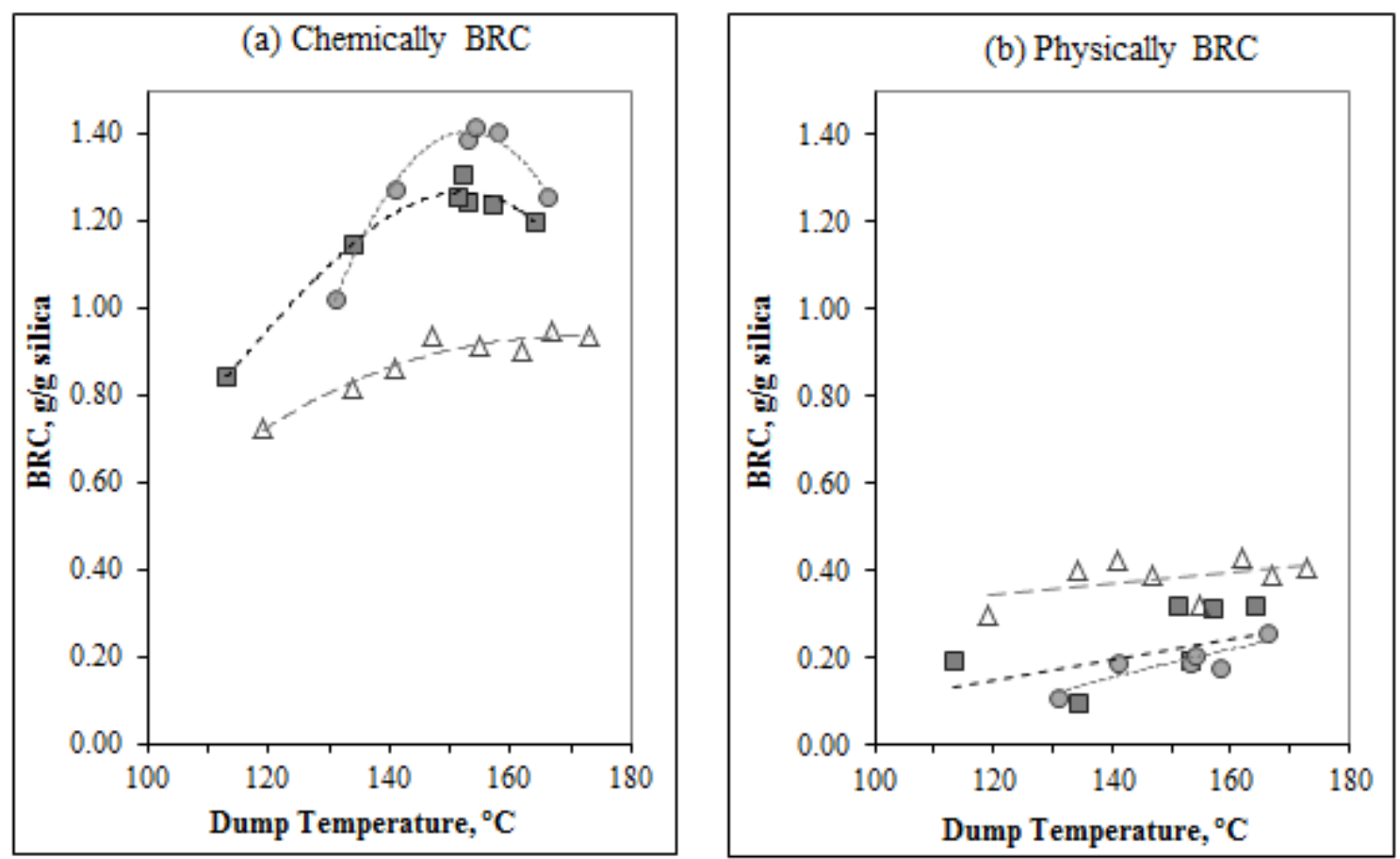

FIG. 11 - Comparison of: (a) chemically and (b) physically bound rubber content of silica compounds containing TESPT at varying dump temperature: $(\boldsymbol{\bullet})$ : NR; $(\bullet)$ : DPNR; $(\Delta)$ : IR. 


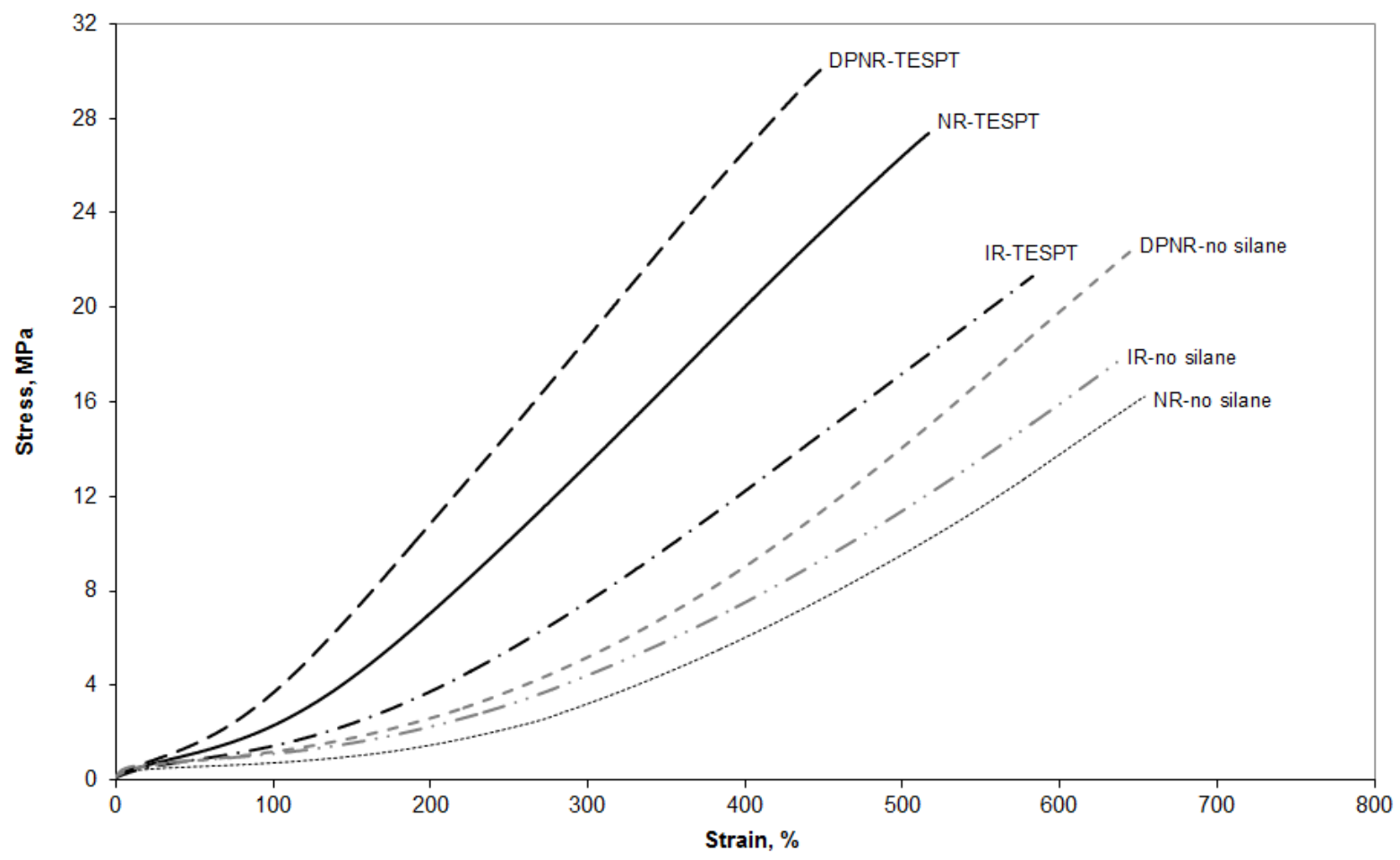

FIG. 12 - Comparison of stress-strain curve between NR-, DPNR- and IR-silica compounds with silane TESPT and without silane. 

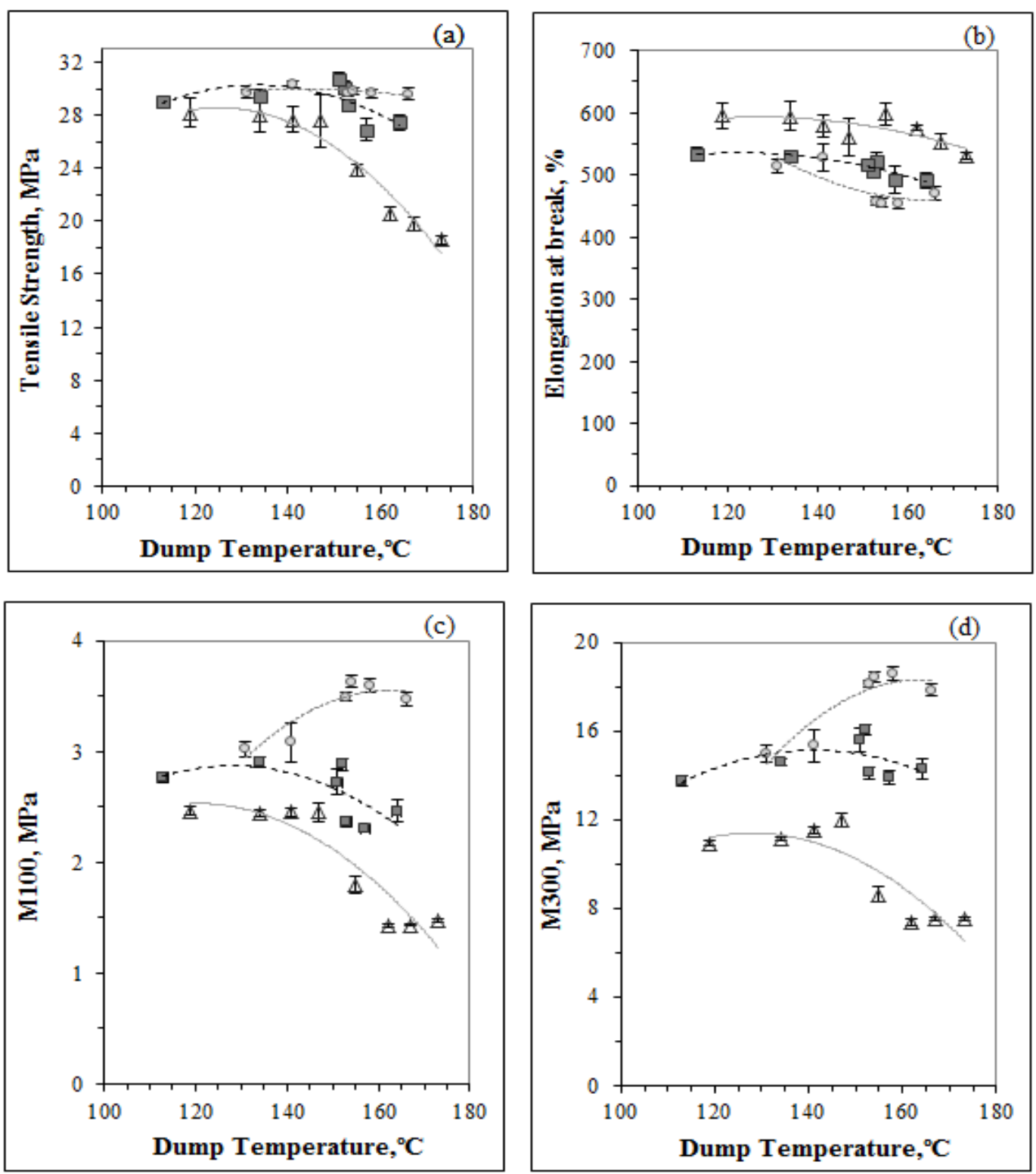

FIG. 13 - Physical properties of silica vulcanizates: (घ):NR; (•):DPNR; $(\Delta)$ : IR;

(a) Tensile strength, (b) Elongation at break, (c) Modulus at 100\% elongation (M100),

(d) Modulus at 300\% elongation (M300). 

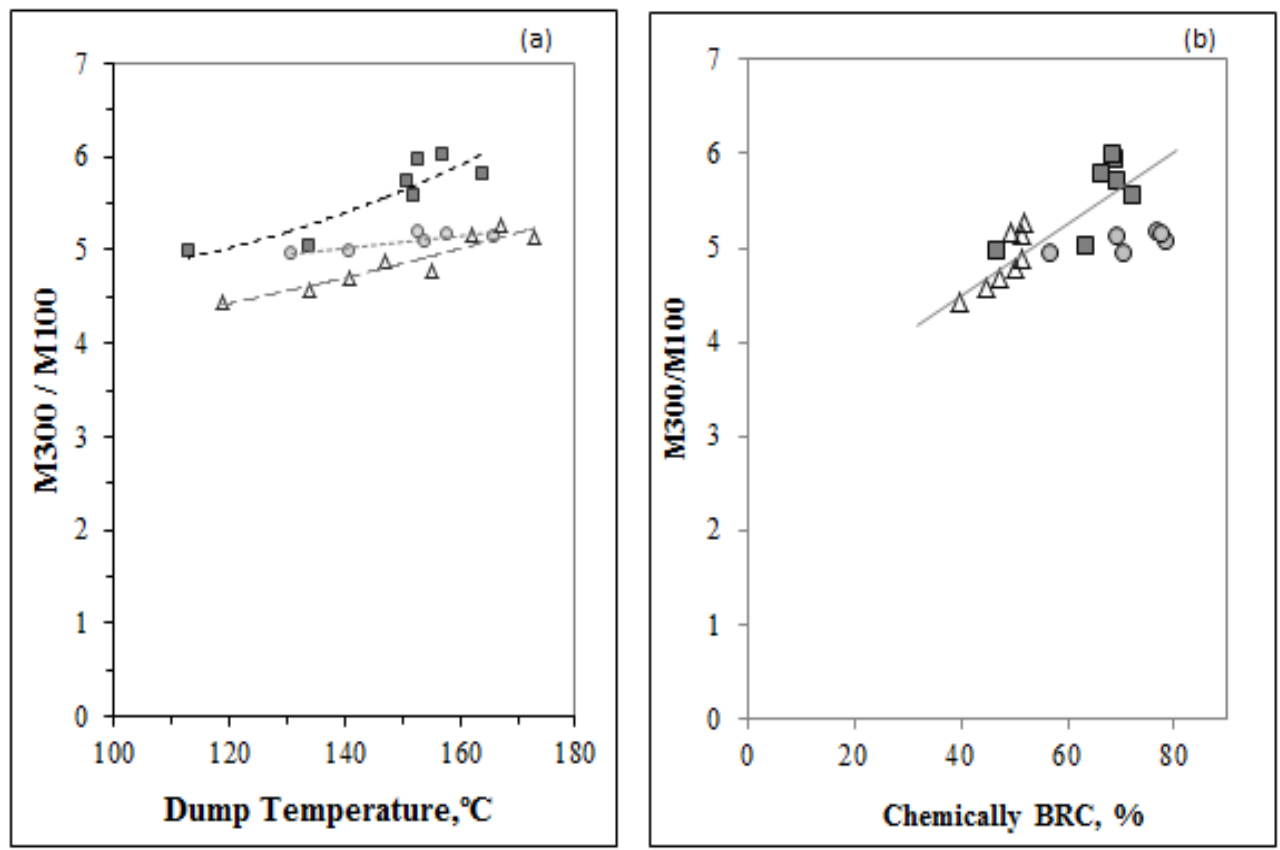

FIG. 14 - Reinforcement index M300/M100 of NR-, DPNR- and IR-silica compounds with TESPT as function of: (a) dump temperature; (b) chemically bound rubber; (匹):NR; $(\bullet): \operatorname{DPNR} ;(\Delta)$ : IR. 


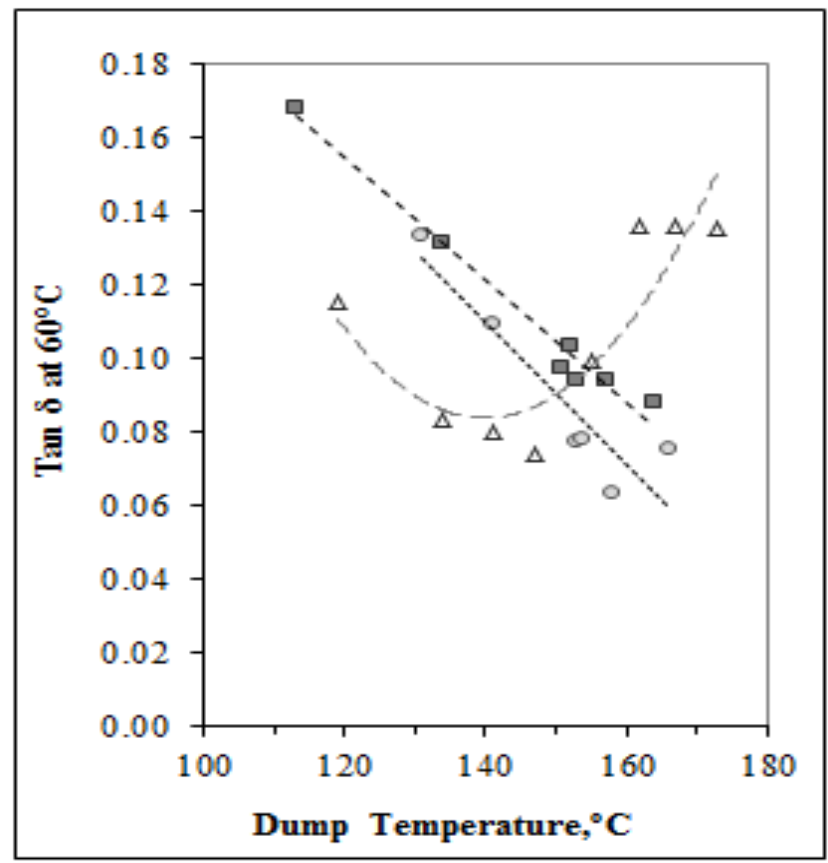

FIG. 15 - The effect of dump temperature on $\tan \delta$ at $60^{\circ} \mathrm{C}$ of silica compounds: ( $\left.\mathbf{a}\right)$ :NR;

$(\bullet): D P N R ;(\Delta):$ IR. 


\section{Figures Captions}

FIG. 1 - Silica-silane-rubber coupling.

FIG. 2 - Typical fingerprint of the masterbatch mixing of the first mixing stage in the internal mixer showing the dump temperature.

FIG. 3 - Mooney viscosities of : (a) masterbatches after $1^{\text {st }}$ mixing, and (b) compounds after $2^{\text {nd }}$ mill mixing of silica-filled compounds at varying dump temperature: $(\mathbf{\square})$ : NR; (•): DPNR; ( $\Delta)$ : IR.

FIG. 4 - Comparison of vulcanization curves at $150^{\circ} \mathrm{C}$ of silica compounds: (a) with silane and (b) without silane.

FIG. 5 - Vulcanization behavior at $150^{\circ} \mathrm{C}$ of the NR compound mixed till different dump temperatures in the first mixing stage.

FIG. 6 - Vulcanization behavior at $150^{\circ} \mathrm{C}$ of the DPNR compound mixed till different dump temperatures in the first mixing stage.

FIG. 7 - Vulcanization behavior at $150^{\circ} \mathrm{C}$ of the IR compound mixed till different dump temperatures in the first mixing stage.

FIG. 8 - Comparison of Payne effect of silica compounds with silane and without silane

FIG. 9 - Payne effect of silica compounds with silane TESPT as a function of dump temperature: (a) unvulcanized samples; (b) vulcanized samples; (匹): NR; (•): DPNR; $(\Delta):$ IR.

FIG. 10 - Effect of dump temperature on Wolff's filler structure parameter, $\alpha_{f}$ of silica reinforced compounds: (匹): NR; (•): DPNR; $(\Delta)$ : IR.

FIG. 11 - Comparison of: (a) chemically and (b) physically bound rubber content of silica compounds containing TESPT at varying dump temperature: (๘): NR; (•): DPNR; $(\Delta)$ : IR. 
FIG. 12 - Comparison of stress-strain curve between NR-, DPNR- and IR-silica compounds with silane TESPT and without silane.

FIG. 13 - Physical properties of silica vulcanizates: (ロ):NR; (•):DPNR; $(\Delta)$ : IR;

(a) Tensile strength, (b) Elongation at break, (c) Modulus at 100\% elongation (M100), (d) Modulus at 300\% elongation (M300).

FIG. 14 - Reinforcement index M300/M100 of NR-, DPNR- and IR-silica compounds with TESPT as function of: (a) dump temperature; (b) chemically bound rubber; ( $\mathbf{a})$ :NR; $(\bullet): \operatorname{DPNR} ;(\Delta)$ : IR.

FIG. 15 - The effect of dump temperature on $\tan \delta$ at $60^{\circ} \mathrm{C}$ of silica compounds: ( $\left.\mathbf{\square}\right)$ :NR; (•):DPNR; $(\Delta)$ : IR. 